\title{
Inversión inmobiliaria en tiempos de auge y crisis: ¿Es la ciudad un producto minero o un derivado financiero?'
}

\author{
Johannes Rehner² y Sebastián Rodríguez-Leiva ${ }^{3}$
}

\begin{abstract}
RESUMEN
Cuando se generan altos ingresos por exportación, una parte se invierte en inmuebles para asegurar valor a largo plazo, impulsando así el crecimiento urbano. Empleando el argumento de la financiarización de la economía, el segundo circuito del capital y la volatilidad de la renta exportadora, este artículo discute en qué medida los ingresos por exportación, la liquidez financiera, y el endeudamiento se relacionan a escala nacional y a modo de caso ilustrativo, se analiza su incidencia en la inversión inmobiliaria en La Serena. Los resultados muestran que a nivel nacional las tendencias del ahorro, el otorgamiento de créditos, y la liquidez financiera, guardan relación con fases de auge y crisis en la exportación. A nivel ciudad, la renta exportadora y la liquidez financiera tienen una importancia significativa en explicar la inversión inmobiliaria en La Serena, mientras que indicadores como la demanda efectiva y el endeudamiento poseen menor aporte en la explicación.
\end{abstract}

Palabras claves: Financiarización, renta exportadora, liquidez financiera, inversión inmobiliaria.

\begin{abstract}
When high export earnings are generated, a part is invested in real estate, to ensure longterm value, and as a result is thus promoting urban growth. By employing the concepts of financialization, second circuit of capital and volatility of export income, this article discusses on national scale to what extent export earnings, financial liquidity and private debt are related. On local scale their impact on real estate investment in La Serena is analyzed by using a quantitative analysis. The results show that the national trends in savings, lending, and financial liquidity, are related to thy cycle of boom and bust of export revenues. At city level, export income and financial liquidity are of significant importance in explaining real estate investment in La Serena, while indicators of effective demand and debt contribute less to the explanation.
\end{abstract}

Keywords: Financialization, export rents, financial liquidity, real estate investment.

Financiado por Conicyt a través del Proyecto Fondecyt 1150636 y Fondap 15110020. Artículo recibido el 17 de agosto de 2016, aceptado el 5 de diciembre de 2016 y corregido el 20 de enero de 2017. 
La relación entre un espacio amplio, generador de valor económico a través de la actividad extractiva y la "metrópolis", en la cual se intercambia la mercadería, y que es el lugar donde la liquidez financiera se transforma en crecimiento urbano, ha sido brillantemente descrito en una historia económica de la ciudad de Chicago y su relación con el Oeste de los Estados Unidos a finales del siglo XIX (Cronon, 1992). Si la economía chilena sigue básicamente el modelo extractivo y exportador heredado desde el siglo XIX, se podría suponer entonces, que en la actualidad el crecimiento de las urbes chilenas se encuentra ligado a los ingresos generados por la actividad exportadora.

En esta línea, se ha demostrado anteriormente que las ciudades del norte chileno viven una condición de auge, debido a los impactos indirectos de la exportación, donde su crecimiento se relaciona con el empleo generado y los sueldos obtenidos en el sector exportador y además, que este auge se expresa en las actividades asociadas a la construcción y otros servicios (Rehner et al., en prensa). A partir de esto, se puede deducir que en términos económicos, la actividad minera ha impactado en las ciudades del norte chileno, a pesar de mostrar características de enclave en el sentido de sus encadenamientos productivos (Phelps et al., 2015).

Sin embargo, estas interpretaciones no han aclarado aún el papel específico del sector financiero en su relación con la exportación y la inversión urbana, por lo que surgen interrogantes como: ¿Cuánto influye la renta del sector exportador en la inversión inmobiliaria? ¿Qué parte de la inversión en vivienda se explica por la liquidez del sistema financiero? ¿De qué forma los flujos financieros responden a fases de auge y crisis? ¿En qué medida la inversión en vivienda se da por endeudamiento de los hogares? Para analizar estas interrogantes, se plantea una discusión en dos escalas geográficas. En primer lugar, se discute la financiarización en Chile y sus regiones, en relación con la actividad exportadora. En segundo lugar, se plantea un cambio de escala, estimando la inversión inmobiliaria presupuestada mediante modelos de regresión para la ciudad de La Serena.

Respecto a la estructura del trabajo, se propone un primer apartado donde se presentan reflexiones teóricas sobre la relación entre financiarización, renta exportadora, crisis y el sector inmobiliario. Seguido a esto, en un segundo apartado se explica la metodología empleada, la que presenta dos escalas principales - una discusión a escala nacional y una aplicación a la ciudad de La Serena. Un tercer apartado presenta un análisis de indicadores financieros, específicamente el ahorro, endeudamiento y los depósitos en el sistema privado de la Administración de Fondos de Pensiones (AFP), diferenciado en tiempo y espacio. Finalmente, en el cuarto apartado, también de carácter empírico, se estima la inversión en inmuebles en la ciudad de La Serena, en función de las variables previamente discutidas.

\section{La relación entre renta exportadora, crisis, financiarización y el crecimiento urbano}

El auge de las exportaciones de América Latina y de Chile a comienzos del presente siglo, provocado principalmente por la demanda asiática de commodities (Rehner et al., 2015), ha generado importantes efectos en la economía nacional de los países exportadores de recursos naturales. Esto se ha traducido en un aumento de los ingresos macroeconómicos por exporta- 
ción, mayor inversión extranjera directa y un incremento considerable de los ingresos fiscales (Coremberg, 2012). Al respecto, se evidencia que en particular entre los años 2000 y 2011, los ingresos fiscales de los países de América Latina aumentaron del 19,6\% al 23,6\% del Producto Interno Bruto (CEPAL, 2013).

Chile no se encuentra ajeno a esta tendencia, en las últimas dos décadas su economía ha experimentado una fase próspera producida por el auge de las exportaciones, las que prácticamente se han cuadruplicado en el período 2002 - 2015, siendo parte importante de esto la exportación de mineral del cobre y cobre refinado. En el período mencionado, la exportación anual de cobre era en promedio de casi 30.000 millones de dólares, aportando un 13,3\% al PIB de Chile (COCHILCO, 2016; Banco Central de Chile, 2016b). Sin embargo, esta prosperidad ha tenido una marcada variabilidad en el tiempo y en el espacio, favoreciendo la exportación y economía de algunas regiones en desmedro de otras, y generando vulnerabilidad frente a la volatilidad de los mercados internacionales (Rehner et al., 2014; Daher, 2015).

Las reflexiones fundamentales de las teorías de modernización de ideología liberal, suponen que con un alto nivel de renta exportadora, aumentan también los ingresos de los hogares y esta mayor liquidez financiera se transforma parcialmente en ahorro e inversión privada. A esto, se suma la suposición de que también las empresas de los rubros "no exportables" se ven impulsadas por el auge exportador, debido a la demanda resultante según lo planteado por Corden \& Neary (1982). Tales impactos de la dinámica del auge exportador en el sector construcción, uno de los "no exportables", ha sido documentada por ejemplo en Canadá (Marchand, 2012). Para Chile, en las regiones receptoras de altos ingresos por exportación minera se evidenció que el auge exportador impulsa el empleo y las remuneraciones en construcción, comercio y hotelería/ gastronomía (Rehner et al., en prensa).

En virtud de lo anterior, se entiende que la renta exportadora fomenta el aumento del consumo, lo que se traduce en crecimiento de las ciudades, debido a que son estos los lugares donde se ofrecen los servicios principalmente. Además, se supone que en fases prolongadas de auge, aumenta también la disponibilidad de capital financiero para ser invertido por parte de los hogares, por el Estado, por las empresas y por los inversionistas institucionales, lo cual se discute a continuación.

\section{La inversión inmobiliaria como vínculo entre la renta exportadora y la ciudad}

David Harvey argumenta en torno a la naturaleza propia del capitalismo y lo vincula con los ciclos inmobiliarios, basándose en la necesidad inherente del capital financiero de reproducirse y por ende, la obligación de reinvertir la liquidez excesiva por ejemplo en inmuebles. En este contexto, Harvey (1985) se ha referido al "segundo circuito del capital" (Fox Gotham, 2009), el cual se basa en el supuesto de que el capital necesita producir rentabilidad a través de la obtención de intereses. Sustentándose en la tesis marxista del decaimiento de la productividad industrial, se deduce que el capital tiende a focalizarse en inversiones financieras e inmobiliarias, materializándose en las ciudades. Este argumento se deriva del trabajo de Henri Lefebvre, el cual ya había destacado el papel clave que juegan las ciudades en esta ecuación: "la ciudad (...) es más que nunca un instrumento útil para la formación de capital, es decir, para la formación, la realización y la repartición de la plusvalía" (Lefebvre, 1983 orig. 1970). En fases en las que abundante capital 
financiero entra a este circuito, necesariamente se genera una alta demanda por objetos inmobiliarios, lo cual provoca un aumento en el valor de estos, permitiendo así una alta rentabilidad del capital invertido en este sector. Esto puede ser incluso desvinculado de la economía real y de la demanda efectiva por inmuebles. De esta forma, el capital se multiplica por su propio comportamiento, mientras no cese el flujo de capital nuevo entrando a un espacio en particular - un círculo que según Harvey tiene característica de esquema piramidal Ponzi, el que necesariamente llega a un momento en el que estalla la burbuja (Harvey, 2011: 11).

Un elemento clave en la argumentación de Harvey (2011), guarda relación con que la dinámica mencionada anteriormente se financia en buena parte por créditos, siendo los hogares (deudores) los que "pagan" por este aumento del valor, a través de los intereses y por asumir riesgo. Esta dinámica tiene dos lecturas, por un lado, bajo un escenario de crecimiento y con prolongado aumento del valor de los inmuebles, los hogares asumen cada vez mayores niveles de deuda. Caso contrario, en un escenario de crisis, son los hogares los que se quedan sin activos cuando el mercado inmobiliario se derrumba. Además, es importante destacar que en dicha dinámica, el papel del capitalista buscando mayor rentabilidad en el segundo circuito del capital, es ejercido en primer lugar por inversionistas institucionales (Cattaneo Pineda, 2011).

En la condición de una economía pequeña, expuesta a la volatilidad de los mercados globales y con una elevada dependencia de un solo commodity, la inversión puede ser interpretada como una reacción racional de variados agentes económicos, entre ellos también individuos y hogares, para reducir los riesgos económicos resultantes de la tesis de la "maldición de los recursos naturales" (Sachs \& Warner, 2001). Particularmente, aquellos riesgos que son el resultado de la volatilidad de los precios del commodity y de la inestabilidad de la moneda nacional, pueden ser mitigados por inversión a largo plazo en activos que no están asociadas a la minería. De acuerdo a esta tesis, se podría suponer que la inversión de recursos generados por el auge, podría mitigar los efectos de las futuras crisis si es que existe un sistema financiero que logre reducir los riesgos a través de la inversión diversificada (Moradbeigi \& Law, 2014).

Para Chile, esto significa que en la última fase de auge del cobre (2004-2008) se produjo una sobreoferta de liquidez financiera, la cual se debió invertir preferentemente en un sector ajeno al minero. Obviamente, depósitos a largo plazo y tasa fija podrían ser opciones sensatas para cumplir con este objetivo. Sin embargo, la inversión inmobiliaria aparece como una opción frecuentemente impulsada por los bancos y elegida por los hogares, ya que posee altas ganancias en fase de auge. Además, prometía ser un "puerto seguro" - por lo menos antes de la crisis subprime predominaba esta percepción - es decir, prometía no sufrir una desvalorización importante en las fases de crisis o estagnación. Incluso posterior a la crisis subprime, el Banco Central consideró los créditos hipotecarios como una inversión de menor riesgo, porque "una fracción importante de estos préstamos cuenta con una garantía real que cubre más del 100\% del crédito" (Matus et al.,2010: 12). La alta rentabilidad proyectada se traduce en la preferencia de las instituciones financieras de colocar recursos en esta actividad, como inversión inmobiliaria propia u otorgando créditos hipotecarios.

En términos generales, se ha demostrado que el precio de la vivienda efectivamente responde en primera instancia a la disponibilidad de ingreso y al costo del crédito (Silva \& Vio, 2015), mucho más que a otras variables relevantes como la oferta de vivienda en el espacio respectivo (Davis \& 
Ortalo-Magné, 2011). Además, el comportamiento del precio de la vivienda demuestra similitudes con otros mercados financieros (Campbell et al., 2009), por lo cual se reconoce una financiarización de este sector, lo que se discute a continuación.

\section{Financiarización de la economía urbana y la bancarización de los hogares}

El concepto "financiarización" hace referencia a la creciente importancia de los mercados financieros y de los intermediarios financieros en la economía y en la política (Pike \& Pollard, 2010: 30) y también, ha sido asociada a la globalización y desregulación (De Mattos, 2008: 24-26). Autores pertenecientes a la "escuela de regulación", han interpretado la fase actual del capitalismo como un nuevo régimen de acumulación, el cual es particularmente financiero, y ampliamente desligado de la economía "real", siguiendo su propia lógica y volatilidad, alternando necesariamente períodos de auge y crisis (Corpataux et al., 2009). Es importante destacar que en esta visión no solamente las crisis pueden tener causas financieras, sin necesidad de fundamento en la economía real, sino el sistema financiero en sí mismo ya no cumple con lo que suponía la visión neoclásica como su principal función y virtud: la asignación "correcta" de los recursos financieros.

Lo anterior se explica por lo siguiente: Mientras que la inversión en factores de producción busca un cierto retorno a largo plazo y tiende a fijar el capital en el espacio, la inversión en instrumentos financieros está marcada por la comparación de rentabilidades y riesgos, razón por la cual tiende a mover los recursos en el espacio a una velocidad mayor, buscando una diversificación de estos riesgos (Corpataux et al., 2009). La discusión crítica de la actual financiarización enfatiza en el papel de los fondos internacionales de inversión y de la movilidad global del capital financiero, lo que genera mayor disponibilidad de capital en cualquier espacio y consecuentemente, es posible su acceso a un menor costo (Daher, 2013). No cabe duda sobre lo asertivo de tal afirmación, pero para economías con alta renta exportadora es pertinente indagar además en el papel de esta renta, de los créditos y del ahorro doméstico, ya que estas economías generan liquidez propia.

Adicionalmente, se deducen consecuencias para los hogares, ya que con mayor ingreso se produce una mayor bancarización, en el sentido de que los hogares disponen de más productos financieros, conteniendo mayores volúmenes, tanto activos como pasivos. En situación de alta renta exportadora, se entiende que los hogares ahorran más, pero también, invierten una parte de sus ahorros a largo plazo, por ejemplo en inmuebles, lo que típicamente se complementa con créditos y por ende, hay un nivel mayor de créditos otorgados a los hogares. Esto se sostiene en un aumento de la capacidad de endeudamiento de los hogares y de las empresas, dado que sus ingresos mejoran la probabilidad de obtener créditos y en particular, créditos de mayor volumen. Esto último es interpretado desde la lectura neomarxista (Lefebvre, 1983 orig. 1970; Harvey, 2011) como expresión de la producción de renta del capital a través del endeudamiento de los hogares, entregando al "capitalista" los intereses de los créditos otorgados.

Por otra parte, se espera que los receptores de ingresos ligados al sector en auge, incluyendo los empleados, inviertan liquidez excesiva obtenida por ejemplo a través de elevados sueldos o pagos de bonificaciones, lo cual plantea que el comportamiento buscador de rentabilidad no sería exclusivo de inversionistas institucionales. Sin embargo, este supuesto resulta cuestionable 
en cuanto al motivo, debido a la existencia de la obligación de invertir, como es en Chile la cotización en el Sistema de Administración de Fondos de Pensiones (AFP), ejemplo emblemático del vínculo entre financiarización e inversión de los hogares (Corpataux et al., 2009). A esto se suma la presión social a consumir, a comprar vivienda y tener la casa propia, lo que finalmente hace cuestionable la "libertad" en el actuar por parte de los hogares al momento de comportarse como "inversionista" y finalmente de endeudarse.

Para los grupos de altos ingresos, la financiarización puede significar una cierta "democratización" de la economía, permitiéndoles participar en rentas obtenidas por el capital. Sin embargo, esto no resulta ser una realidad generalizada para la mayoría de la población, puesto que simplemente no disponen de los recursos a invertir y también, debido a una falta de conocimiento muy específico. Por ende, se debe considerar que la participación de los hogares en esta financiarización tiende a profundizar y reproducir las desigualdades sociales (Pike \& Pollard, 2010: 34) o simplemente produce un endeudamiento por consumo como ha sido demostrado para ciudades pequeñas en Chile (Arboleda, 2015).

\section{Crédito y crisis en el contexto de la financiarización}

A partir de la crisis subprime se ha enfatizado en que las crisis financieras no son fenómenos raros, generados por constelaciones excepcionales, sino que estas son comunes, propias del sistema financiero y ligadas al endeudamiento (Reinhart \& Rogoff, 2009; Gorton, 2012). Hace décadas, Hyman Minsky había planteado la tesis de la "inestabilidad financiera" (Raines \& Leathers, 2008), la cual sostiene que los mismos mercados financieros necesariamente producen ciclos de auge y crisis, debido a que en fases prósperas abunda el optimismo, y con esto, bajan los estándares de evaluación de riesgo y aumentan las expectativas de rentabilidad, lo que tiene como consecuencia un exagerado nivel de inversión en instrumentos de alto riesgo (Wolfson, 2002: 393). Cuando se subestima el riesgo, se otorga un gran número de créditos que no serán pagados en momentos coyunturales desfavorables, lo que implica que el sector financiero registra pérdidas y finalmente, hay escasez de capital financiero.

Si bien la tesis de Minsky se refiere por sobre todo al otorgamiento de créditos comerciales, el argumento se ha aplicado a los créditos hipotecarios, particularmente posterior a la crisis subprime. En la visión tradicional, la función principal de los créditos hipotecarios es posibilitar el acceso a recursos financieros para aquellos hogares que no disponen de suficientes ahorros para comprar bienes inmobiliarios. Sin embargo, en el contexto de la financiarización, el otorgamiento de créditos hipotecarios se ha convertido en un instrumento de inversión financiera que responde principalmente a la necesidad de asignar liquidez y producir rentabilidad, perdiendo de este modo su función original (Waldron, 2016). Por esto, la reflexión de Minsky se hace particularmente relevante, ya que la excesiva liquidez en tiempos de auge provoca que las prácticas de otorgamiento se tornen menos rigurosas y que los valores de los inmuebles sean sobreestimados. Al respecto, en un estudio de distintas zonas urbanas de Estados Unidos, Brueckner et al. (2012: 230) demuestran una mayor probabilidad de entregar créditos a clientes subprime, cuando las expectativas de precios futuros son mayores, argumentando que esta práctica de otorgar créditos es causa y consecuencia de burbujas en el mercado de vivienda.

El endeudamiento de los hogares es un riesgo para ellos y también macroeconómico cuando la carga de servicios a la deuda en relación a su ingreso sobrepasa un umbral crítico o bien, esta 
carga aumenta sustancialmente en un lapso corto o cuando las garantías de cuales disponen (los inmuebles) estén sobrevalorados. Es probable que tal situación acontezca en una crisis, sobre todo cuando había previamente un fuerte auge, dado que el ingreso disponible de una parte importante de los hogares disminuye, afectando su capacidad de pago. Esto sucede independientemente si la crisis es de naturaleza doméstica, de exportación o debido a la financiarización misma. La caída de precios de vivienda en tal situación tendría un doble efecto negativo, reduciendo el valor de los activos de cuales disponen los hogares y a la vez, disminuyendo el valor de la seguridad de cual disponen los acreedores a través de las hipotecas (Banco Central de Chile, 2014).

A partir de este reconocimiento teórico es preciso considerar cómo esta reflexión se hace geográficamente relevante. En primer lugar, se puede suponer que economías urbanas altamente involucradas en los flujos financieros globales y con un fuerte énfasis en lo inmobiliario sufrirán con las crisis globales financieras, debido a la rapidez y la liberalización de los flujos financieros. En este sentido, Méndez (2013) ha discutido la crisis financiera en España, particularmente en Madrid, destacando la necesidad de un análisis multi-escalar, ya que la crisis en Madrid responde a tendencias del capitalismo global y también, es configurada por condiciones específicas en la capital española. El caso de México es elocuente en este sentido, ya que la crisis financiera-hipotecaria de Estados Unidos y de escala global ha tenido repercusiones sobre el ingreso de capital, la formación de capital fijo y otras esferas de la economía mexicana, incluyendo la escala local (Cuevas Ahumada, 2013). Entre otros, el contexto urbano de México posterior a la crisis, ha estado marcado por la fragilidad financiera y la financiarización de la economía a la vez. Esto incluye entre otros aspectos, al creciente papel de los créditos hipotecarios y su relación con los mercados financieros globales (Isunza Vizuet, 2013: 231). Durante la próspera fase económica en México previo a la crisis (2000-2007), el valor de los créditos hipotecarios aumentó siete veces. De forma posterior, como efecto de la crisis coinciden la falta de liquidez del sistema financiero, una situación problemática en el mercado laboral y un aumento de los créditos morosos (Isunza Vizuet, 2013: 233-234). Por su parte, Handke (2013) evidenció para España que las interdependencias del sector construcción, inmobiliario y financiero, explicaron en parte el auge económico, pero jugaron un rol aún más importante en el desencadenamiento de la crisis 2008/2009. Esto, debido a la desaceleración que experimentó el sector inmobiliario, lo cual repercutió en la rentabilidad y la morosidad en el sistema financiero español (Banco de España, 2014). Asimismo, las tasas de créditos impagos por parte del sector privado y los hogares, ascendió rápidamente desde apenas $0,8 \%$ a $5,0 \%$ entre 2007 y 2009 . Tal situación, redujo el crecimiento del resto de los sectores de la economía española, evidenciando el carácter sistémico de la crisis subprime en este caso (Handke, 2013). De manera similar, en México la morosidad de los créditos hipotecarios subió drásticamente durante la crisis, superando el $5 \%$ en 2009 y la de los créditos de consumo llegó a casi 10\% (Ramírez de la O, 2009: 7).

En términos geográficos se puede esperar que las crisis se manifiestan de manera distinta, en función de la participación de los flujos globales en las economías locales y regionales, dado que esto implica diferentes niveles de susceptibilidad y de posibilidad de contagio (Daher, 2003). La lógica de esta relación es que los ingresos de capital por vía de exportación y por recepción de inversión, están sincronizados y afectan fuertemente las principales ciudades, por las que estos flujos pasan y también se materializan (Daher, 2003).

Adicionalmente, hay que considerar las decisiones de agentes públicos y las constelaciones económicas nacionales que influyen en la manera en cómo las crisis se expresan en un espacio 
en particular. La política monetaria y fiscal de Chile ha favorecido la inversión con bajas tasas de interés, en comparación con otros países de América Latina, y ha aplicado inversión pública anticíclica, particularmente durante la crisis en el año 2009 (De Gregorio, 2014). Si bien la naturaleza de las crisis financieras ha sido asociada con fallas en la evaluación de riesgo, estructuras de inversión piramidal, de tipo "Ponzi" y otras "fallas de mercado", la bonanza, por ejemplo la generada por el crecimiento de China y su efecto sobre los precios de commodities, es un factor clave a discutir (Corbo et al., 2011: 14).

\section{Metodología}

El primer apartado de resultados se basa en una discusión de tendencias de varios indicadores referidos a las colocaciones (créditos), las captaciones (ahorro) de los hogares, los depósitos en el sistema previsional AFP y los retiros del sistema previsional voluntario APV. Estos permiten contrastar regiones mineras con las regiones del resto del país (sin considerar RMS). En cuanto a la temporalidad de los datos y el análisis, este comprende los años 2005 - 2015, permitiendo contrastar la fase del auge exportador (2005-2008), la fase marcada por la crisis subprime 2008/2009, y la fase de rápida recuperación con un sucesivo enfriamiento.

La metodología empleada en el último apartado de este trabajo consiste en la construcción de modelos de regresión (OLS), para estimar el presupuesto de los permisos de edificación de obra nueva en vivienda en la comuna de La Serena, en función de variables asociadas a la liquidez financiera, el otorgamiento de créditos, el balance de inversión de cartera, la exportación y las remuneraciones. Estos se complementan con dos variables, indicadores de la demanda real por vivienda: la población y la demanda turística, medida como número de pernoctaciones. La periodicidad mensual de estos datos permite un análisis detallado del comportamiento y la tendencia de cada variable. Las variables incluidas en esta modelación están constituidas en tres escalas geográficas, correspondientes al nivel comunal (La Serena), regional (Región de Coquimbo) y nacional (Cuadro No 1).

Se realizaron tres tratamientos a los datos. Primero se realizó un suavizado del presupuesto de los permisos de edificación debido a su alta variabilidad. Por ello, se ocupó el promedio móvil de tres meses para estimar los valores mensuales. Para complementar esto, un segundo tratamiento fue la desestacionalización de dicha variable y del número de pernoctaciones con la herramienta "análisis de serie de tiempo". El tercer tratamiento fue un desfase de algunos meses aplicado a las variables explicativas (independientes), frente a la variable dependiente (presupuesto inmobiliario). El desfase de las remuneraciones en otros rubros (- 6 meses), valor de la exportación de cobre (- 12 meses), volumen de las cotizaciones en AFP (- 12 meses), monto total de los retiros de APV (- 4 meses), balance financiero de cartera (- 12 meses) y de las pernoctaciones (- 12 meses) se definió a partir de un análisis de sensibilidad temporal de cada variable. Las demás variables se ingresaron sin desfase.

La modelación se realizó con el software SPSS 23, calculando primero correlaciones bivariadas para el conjunto de variables involucradas en el análisis. A partir de esto, se procedió a construir dos modelos de regresión, los cuales cumplen con las condiciones: tener un $\mathrm{R}^{2}$ corregido superior a 0,5; ser significativos (al nivel de 0,01) y mostrar valores satisfactorios en el test de multicolinealidad (tolerancia $>0,1$ y VIF $<7,0$ ). 
Cuadro $\mathrm{N}^{\circ} 1$

Variables en el modelo de regresión - estadísticas descriptivas

\begin{tabular}{|c|c|c|c|c|c|}
\hline \multirow[b]{2}{*}{ Escala } & \multirow[b]{2}{*}{ Fuente } & \multirow[b]{2}{*}{ Variables } & \multicolumn{3}{|c|}{ Estadísticas descriptivas } \\
\hline & & & $\begin{array}{c}\text { Número } \\
\text { de } \\
\text { meses }\end{array}$ & Media & $\begin{array}{l}\text { Desviación } \\
\text { estándar }\end{array}$ \\
\hline Comuna & DOM & $\begin{array}{c}\text { Presupuesto permisos } \\
\text { edificación (obra } \\
\text { nueva, vivienda, en } \$ \text { ) }\end{array}$ & 132 & 2.946.179.506 & 1.607.428.963 \\
\hline Comuna & INE & Población ${ }^{4}$ & 132 & 195.882 & 13.052 \\
\hline Región & SBIF & $\begin{array}{c}\text { Colocaciones } \\
\text { bancarias nuevas } \\
(\text { en } \$)\end{array}$ & 132 & 14.911.196.232 & 19.134.987.335 \\
\hline Región & SBIF & $\begin{array}{l}\text { Volumen créditos } \\
\text { hipotecarios (en \$) }\end{array}$ & 132 & 521.682.265.299 & 253.126.130.235 \\
\hline Región & INE & $\begin{array}{l}\text { Número de } \\
\text { pernoctaciones }\end{array}$ & 132 & 58.352 & 11.789 \\
\hline Región & $\begin{array}{c}\text { Superintendencia } \\
\text { de Pensiones }\end{array}$ & $\begin{array}{c}\text { Remuneración } \\
\text { promedio otros rubros } \\
\text { (mensual, en } \$)\end{array}$ & 126 & 496.629 & 112.431 \\
\hline Nación & Aduanas & $\begin{array}{c}\text { Valor de la exportación } \\
\text { en minería (en \$) }\end{array}$ & 120 & 1.507.727.375.479 & 367.285.565.482 \\
\hline Nación & $\begin{array}{c}\text { Superintendencia } \\
\text { de Pensiones }\end{array}$ & $\begin{array}{c}\text { Volumen acumulado } \\
\text { cotizaciones en } \\
\text { AFP (en \$) } \\
\end{array}$ & 120 & 62.345.554.440.757 & 17.504.668.990.464 \\
\hline Nación & $\begin{array}{c}\text { Superintendencia } \\
\text { de Pensiones }\end{array}$ & $\begin{array}{l}\text { Monto de los retiros } \\
\text { en APV (en \$) }\end{array}$ & 128 & 7.655.640.755 & 4.931.323.040 \\
\hline Nación & $\begin{array}{c}\text { Superintendencia } \\
\text { de Pensiones }\end{array}$ & $\begin{array}{l}\text { Remuneración } \\
\text { promedio minería } \\
\text { (mensual, en \$) }\end{array}$ & 132 & 1.023 .695 & 183.212 \\
\hline Nación & Banco Central & $\begin{array}{c}\text { Balance Financiero de } \\
\text { Cartera }^{6}(\text { en } \$)\end{array}$ & 132 & 125.512.833.667 & 401.611.994.430 \\
\hline
\end{tabular}

DOM: Dirección de Obras Municipales

INE: Instituto Nacional de Estadísticas

SBIF: Superintendencia de Bancos e Instituciones Financieras de Chile

Fuente: Elaboración propia

Se ocupó la estimación oficial anual. Los valores mensuales se obtuvieron mediante interpolación, suponiendo una tasa de crecimiento constante durante cada año y suponiendo que el valor oficial de población de cada año corresponde al mes de julio.

Se excluyó el sector agricultura del cálculo del promedio de las remuneraciones en los otros sectores.

S De la cuenta financiera del Banco Central se consideraron los flujos netos en inversión de cartera, instrumentos financieros derivados y otra inversión de los bancos, fondos de pensiones, otras instituciones financieras, empresas y hogares. 


\section{Tesis y situación actual en una economía pequeña, abierta y con relevante renta exportadora: Chile}

A continuación, se revisa la situación de varios indicadores financieros en Chile, guiado por una serie de tesis que se deducen en base a la discusión teórica. Primero, es preciso diferenciar las fases de auge y crisis de la exportación, cuantificando el valor total de las exportaciones de cobre del país, diferenciado por mes, en base del promedio móvil (Figura № 1).

Figura No 1

Valor total de la exportación de cobre en Chile (mensual 2005-2015)

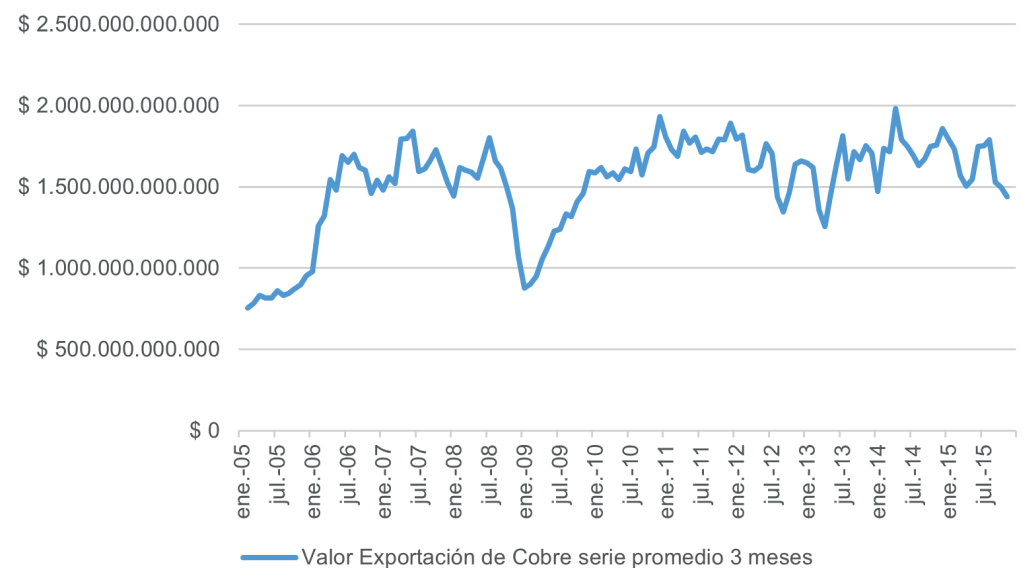

Fuente: Elaboración propia basado en datos de COCHILCO (2016)

Se evidencia el vertiginoso crecimiento entre 2005 y 2007, y se observa que al final del año 2008, cuando ya había estallado la crisis financiera global, la exportación decae rápidamente - lo que permite hablar de una crisis de exportación entre fines de 2008 y la mitad del 2009. La rápida recuperación tiene como consecuencia que al inicio del año 2011 el valor total de la exportación ya había recuperado su nivel previo a la crisis.

Según lo discutido en el apartado teórico sobre la renta exportadora y la bancarización de los hogares, se espera que el sector en auge produzca mayor ingreso de los hogares y que esto se traduzca en una mayor participación de los hogares en el sistema financiero a través del ahorro. Por ende, con respecto al ahorro en Chile se plantean las siguientes tesis: (1) El aumento del valor de los depósitos en fase de auge minero es mayor que en fase de crisis y de estagnación; (2) En las regiones mineras el valor de ahorro per cápita es mayor que en las demás regiones; y (3) El aumento de depósitos en regiones mineras es mayor que en los demás regiones?.

En este apartado se contrasta la situación en las regiones mineras (Tarapacá, Antofagasta, Atacama y Coquimbo) con el resto del país, correspondiendo a las regiones restantes, exceptuando a la Región Metropolitana. 
Las captaciones bancarias en Chile (Figura $N^{\circ} 2$ ) evidencian un elevado crecimiento promedio anual en la fase de auge minero (2005 - 2008), para luego frenarse fuertemente en el período de crisis entre los años 2009 y parte del año 2010. Después de la crisis financiera global, repunta con un muy alto crecimiento en el año 2011 y luego su crecimiento comienza a descender paulatinamente hasta 2014. De esta forma, el comportamiento de las captaciones y depósitos bancarios en Chile muestra una marcada relación con el auge exportador y la crisis global. En particular, por un lado se observa que las regiones mineras (Tarapacá, Antofagasta, Atacama y Coquimbo) poseen en promedio un mayor volumen de ahorro per cápita. Por otro lado, se reconoce un aumento sostenido de las captaciones en el tiempo, donde las regiones mineras tienen un comportamiento similar al resto del país. De esta forma, se confirman las primeras dos suposiciones, pero la tercera no se cumple.

Figura No 2

Volumen (\$) y crecimiento anual captaciones per cápita (\%)

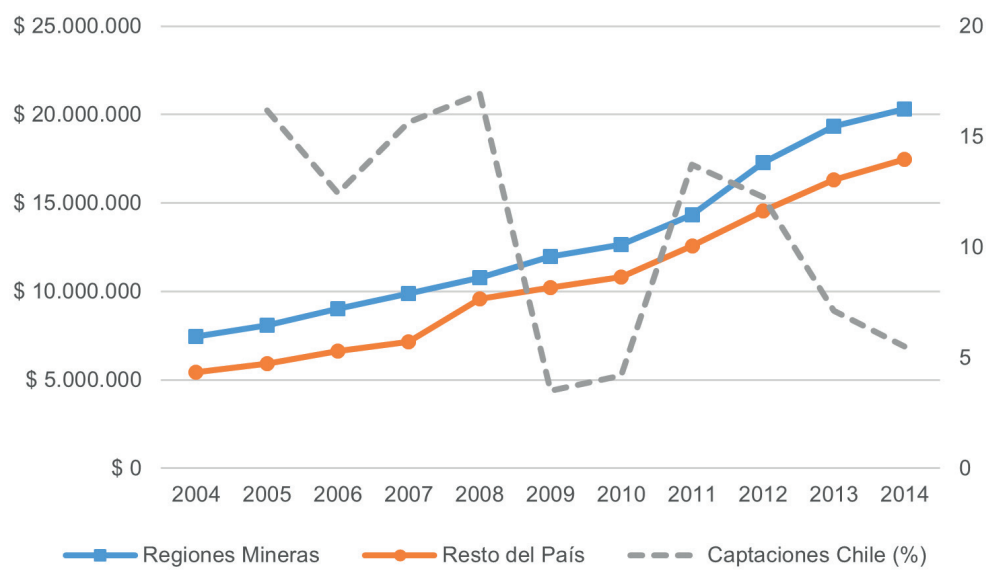

Fuente: Elaboración propia basado en datos de SBIF (2015) e INE (2016)

El postulado de Minsky y la evidencia de mayores ingresos en tiempos y espacios de auge exportador, derivan en las siguiente hipótesis referidas al volumen de créditos otorgados: (4) El aumento de los créditos en fase de auge minero es mayor que en fase de crisis. (5) El valor per cápita de los créditos en regiones mineras es mayor que en las demás regiones. (6) La velocidad de aumento de las colocaciones per cápita en las regiones mineras es mayor.

Respecto a la dinámica de los créditos otorgados, se observa un alto crecimiento durante la fase de auge minero, para luego descender abruptamente en el año 2009, marcado por la crisis financiera y la baja en la exportación del cobre, y finalmente recuperar su crecimiento, manteniéndose relativamente estable pero por debajo del nivel registrado durante el auge (Figura $N^{\circ} 3$ ). La tendencia a nivel regional indica que en las regiones de carácter minero se otorgan mayores créditos per cápita que en el resto del país. Asimismo, se evidencia que con el paso del tiempo, la diferencia entre regiones mineras y resto del país aumenta, ya que en el año 2004 la diferencia en el valor de los créditos por persona fue de aproximadamente $\$ 250.000$, para luego aumentar a más de $\$ 1.000 .000$ en el año 2014. De esta forma, las tesis 4,5 y 6 se cumplen en Chile, mos- 
trando que una mayor renta exportadora corresponde a un mayor otorgamiento de créditos en espacio y en tiempo.

Figura No 3

Volumen (\$) y crecimiento anual colocaciones per cápita (\%)

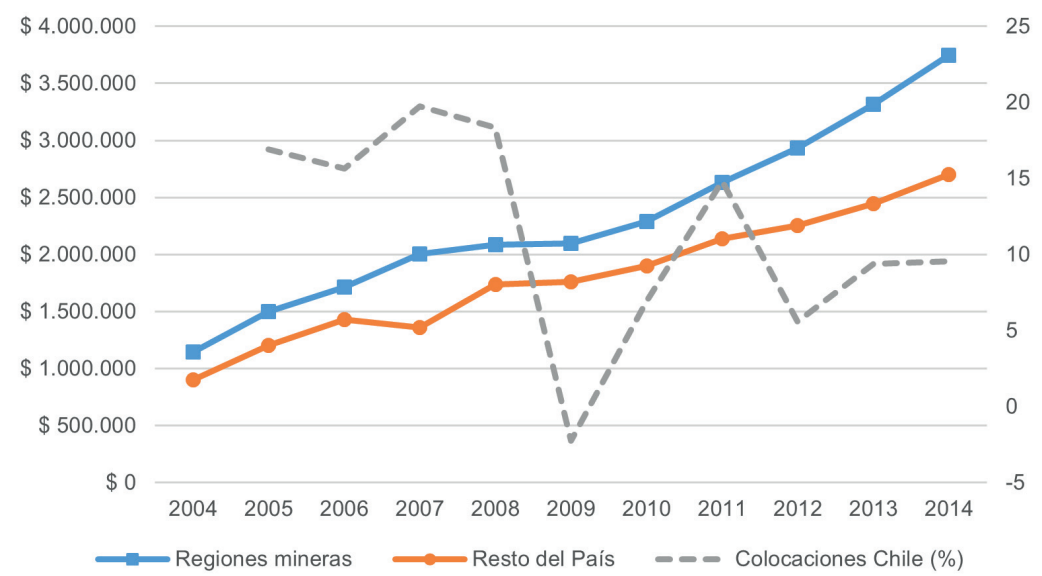

Fuente: Elaboración propia basado en datos de SBIF (2015) e INE (2016)

En base a las reflexiones teóricas sobre el comportamiento racional frente a la maldición de los recursos, se espera una tendencia hacia la diversificación y la inversión a largo plazo, sobre todo cuando hay abundancia de capital financiero, por lo cual se postula en cuanto a la composición de los créditos: (7) La participación de los créditos hipotecarios en el total de las colocaciones aumenta en el tiempo, particularmente en fases de auge; (8) En las regiones mineras se registra una mayor participación de los créditos hipotecarios en el total de las colocaciones; (9) El valor de los créditos hipotecarios aumenta en el trascurso del tiempo, pero se ve frenado por la crisis; y (10) En las regiones mineras los créditos hipotecarios tienen un valor mayor que en las demás regiones.

Efectivamente, la participación de los créditos hipotecarios en las colocaciones bancarias totales muestra una tendencia al aumento entre 2004 y 2014 (Figura No 4), por lo cual se sostiene que en una fase prolongada de altos ingresos y liquidez, no solo se produce un aumento de los créditos hipotecarios, sino que estos créditos crecen sobre proporcionalmente. Notablemente esta tendencia no se vio afectada por la crisis financiera global 2008/2009, sino que todo lo contrario, durante la crisis esta tasa aumenta, sobre todo en las regiones mineras. Se observa un leve estancamiento / reducción de esta tasa recién después de la crisis, entre fines de 2010 y mitad del año 2012. Adicionalmente a la tendencia de aumento general, se observa un inesperado salto en el período 2005-2006, posiblemente explicado por un impulso estatal, que consistió en el otorgamiento de subsidios a la clase media y grupos emergentes, dado que el número de hogares beneficiados casi se duplicó en un año (MINVU, 2014). En cuanto a la diferenciación espacial, la participación de los créditos hipotecarios en las colocaciones otorgadas en las regiones mineras supera claramente al resto de las regiones. 
Referido al valor de deuda hipotecaria por persona (Figura $N^{\circ} 5$ ), se evidencia un crecimiento rápido, tal como se esperaba, pasando en las regiones mineras de 20 UF (Unidad de Fomento) a más de 50 UF $^{8}$ y de 10 UF a 30 UF en las regiones no mineras. A modo de comparación, cabe destacar que en Irlanda, antes de la crisis subprime, el volumen de los créditos hipotecarios creció mucho más rápido, cuadruplicándose en ocho años (Waldron, 2016). Asimismo, en términos temporales se observa que - salvo un pequeño freno al inicio del año 2008 - el crecimiento se mantiene continuo hasta 2012, siendo a partir de ese año cuando se produce un estancamiento del valor de los créditos hipotecarios por persona. Llevado a escala regional, se observa no solamente que el valor de los créditos hipotecarios por habitante en las regiones mineras supera claramente al resto del país, sino que esta brecha aumenta partir de la crisis del periodo 2008 - 2009 hasta 2012.

Figura $\mathrm{N}^{\circ} 4$

Créditos Hipotecarios en total de colocaciones (\%)

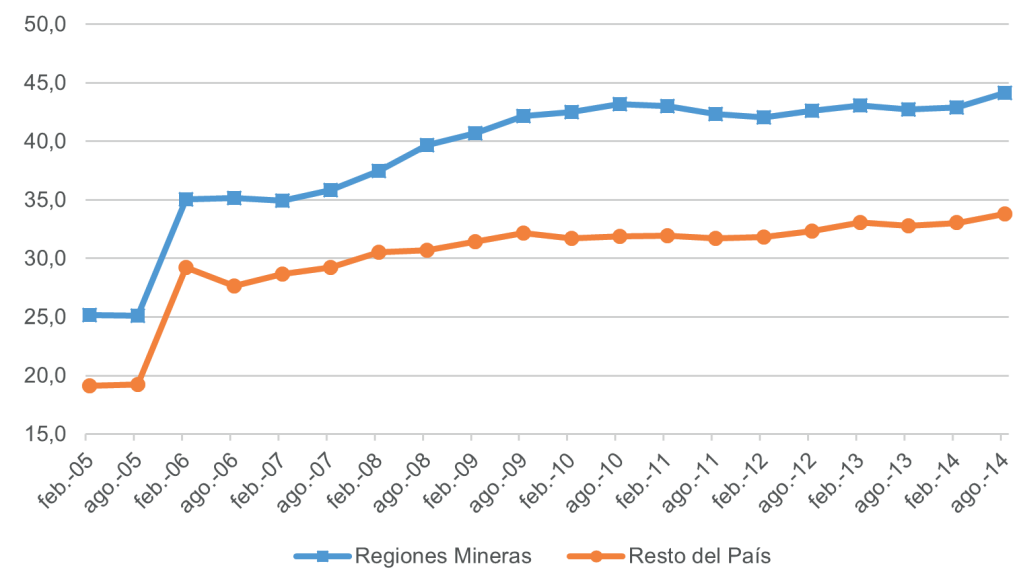

Fuente: Elaboración propia basado en datos de SBIF (2015) e INE (2016)

En resumen, se confirman las tesis 7, 8, 9 y 10 mostrando la creciente importancia y el mayor valor de los créditos hipotecarios en tiempo de crecimiento y espacio minero. Sin embargo, cabe mencionar que el freno no se produce en la crisis sino que de forma posterior, a partir de 2010 y 2012 respectivamente.

Considerando la discusión teórica sobre el endeudamiento y los riesgos asociados, se espera que debido a la liquidez asociada a la exportación: (11) se produzca un mayor otorgamiento de créditos de consumo en las regiones mineras; (12) un mayor dinamismo de los créditos de consumo en tiempos de auge y su reducción en tiempos de crisis; (13) un aumento de los problemas de endeudamiento durante la crisis con repercusión en los meses posteriores; y (14) un mayor nivel de deudas con problemas en las regiones mineras, como resultado de un otorgamiento excesivo.

Hay que considerar que este valor se presenta por persona (no por hogar) y se calculó sobre el total de la población de las regiones, no sobre el total de las personas que tienen crédito. Por ende, no representa el valor promedio de los créditos, sino que el nivel promedio de deuda hipotecaria de todas las personas de la región respectiva. 
Figura No 5

Valor Créditos Hipotecarios (UF/persona)

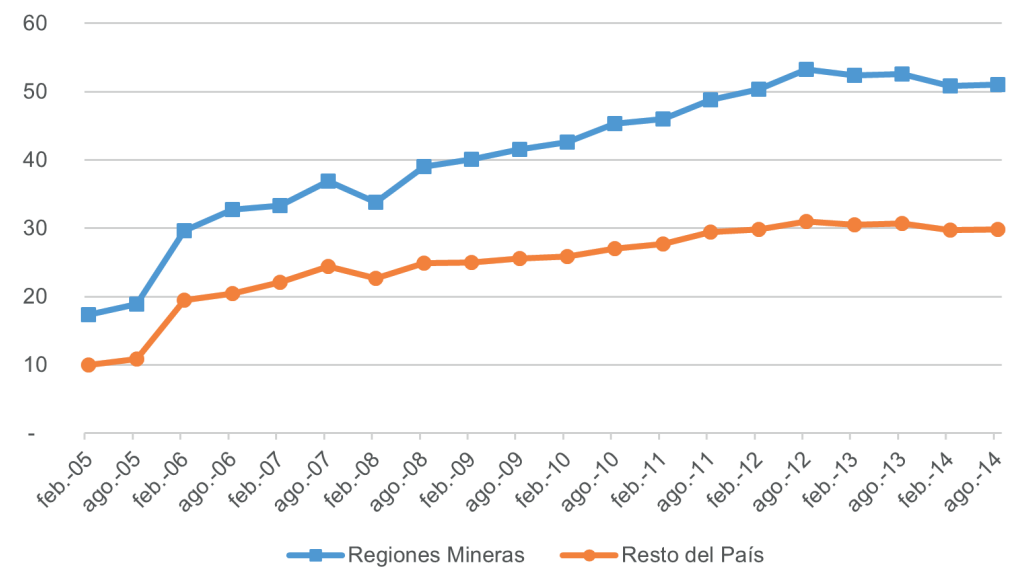

Fuente: Elaboración propia basado en datos de SBIF (2015) e INE (2016)

Los créditos de consumo parecen un fenómeno generalizado en Chile, ya que las regiones mineras y el resto del país tienen un comportamiento muy similar, siendo sólo levemente superior la importancia de los créditos de consumo en las regiones de orientación minera. Sin embargo, en términos temporales, es notable que en pleno auge (2004 hasta 2007) y en los meses previos a la crisis, el otorgamiento de créditos de consumo aumente muy rápidamente, a tasas anuales por sobre $20 \%$ (Figura $N^{\circ} 6$ ). El efecto de esto es un rápido aumento del nivel de endeudamiento en Chile, como porcentaje del PIB, previo a la crisis (Arraño \& Velásquez, 2012). Se evidencia el crecimiento muy rápido de este tipo de créditos en tiempos de auge, mostrando mayor volatilidad que el de los créditos hipotecarios.

Crecimiento del valor de las colocaciones (\%, año a año)

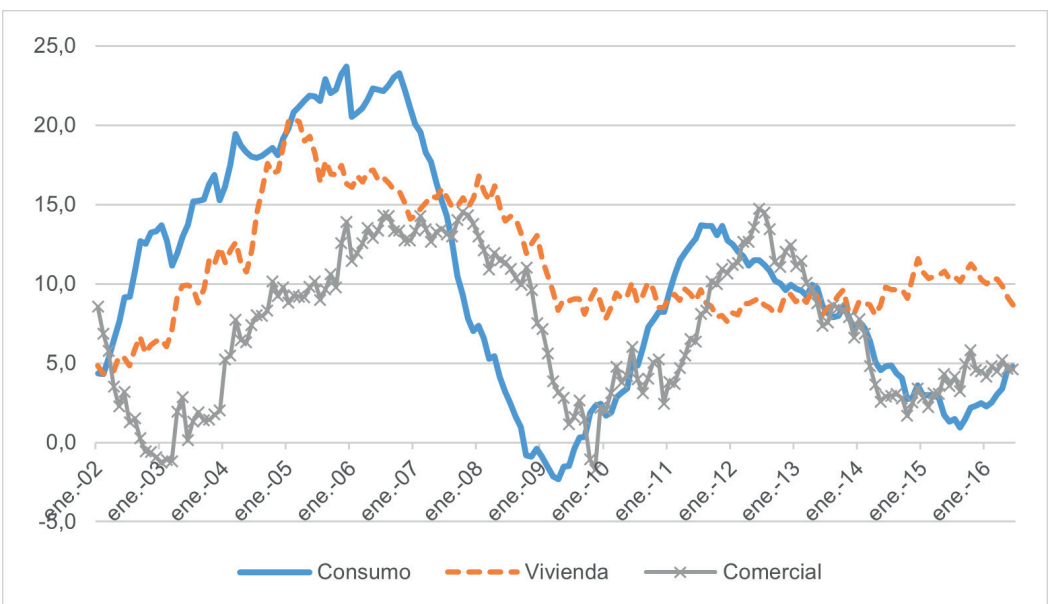

Fuente: Elaboración propia basado en datos de SBIF (2015) y Banco Central de Chile (2016a) 
Figura No 7

Colocaciones vencidas en el total (\%)

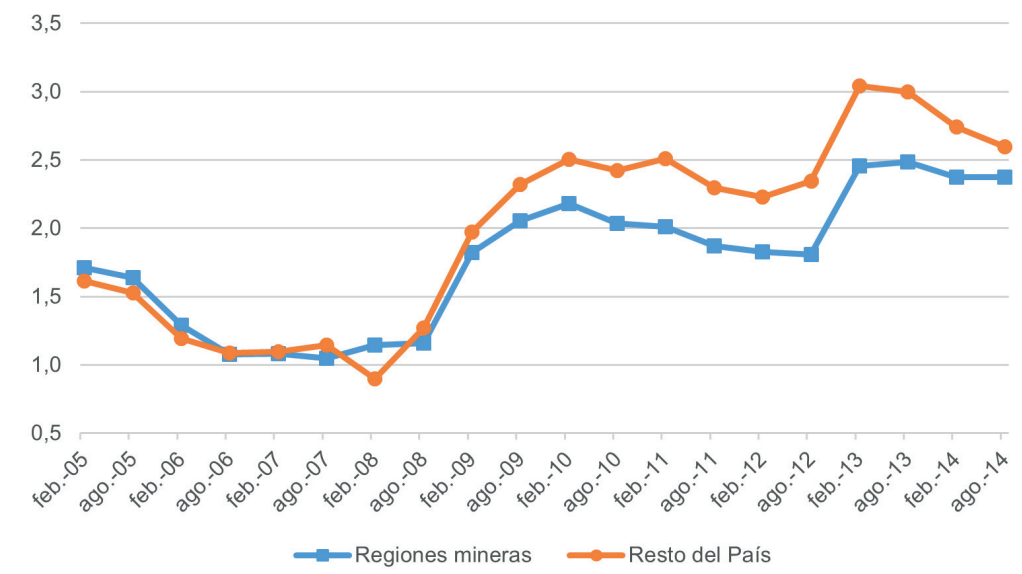

Fuente: Elaboración propia basado en datos de SBIF (2015) y Banco Central de Chile (2016a)

Otro elemento relevante corresponde al comportamiento de los créditos: el período 2008 - 2009 está marcado por el aumento considerable de situaciones problemáticas de endeudamiento de los hogares (Figura No 7), donde las colocaciones vencidas pasaron de un $1 \%$ (previo a la crisis) a un 2,5\% (posterior a la crisis). Seguido a la crisis, se evidencia un estancamiento de las colocaciones vencidas en un nivel relativamente elevado, para luego en 2013 experimentar un nuevo leve ascenso y situarse alrededor del $2,8 \%$ del total de las colocaciones. El comportamiento de la morosidad muestra una pauta similar con un marcado impacto de la crisis (Figura $N^{\circ} 8$ ).

Figura No 8

Morosidad tarjetas de créditos (\%)

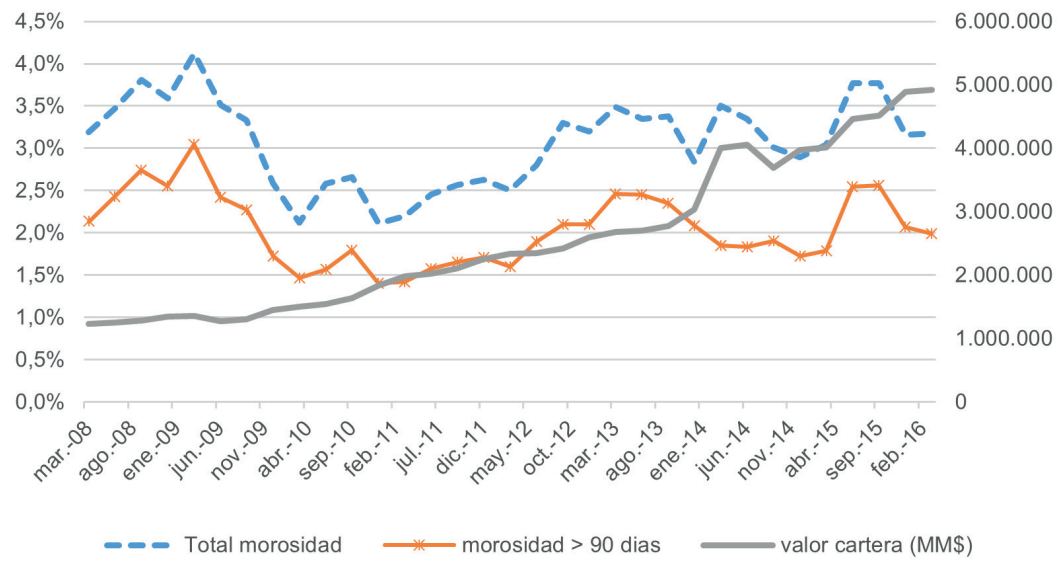

Fuente: Elaboración propia basado en datos de SBIF (2016) 
En términos espaciales, resulta llamativo que los marcados ascensos que han experimentado las colocaciones vencidas, parecen ser más fuertes en el resto del país que en las regiones mineras, siendo el año 2009 el punto clave donde esta brecha aumenta, para luego mantenerse prácticamente constante en el tiempo. Se puede deducir entonces, que a través del círculo financiero, las regiones mineras reciben mayores beneficios del auge exportador, pero son el resto de las regiones las que sufren más del efecto negativo asociado al endeudamiento.

Si bien las colocaciones vencidas experimentaron un fuerte incremento, resulta cuestionable si el nivel de endeudamiento de los hogares chilenos debe ser considerado un problema en la actualidad. Por un lado, el hecho de que el $3 \%$ de las colocaciones estén vencidas puede parecer bajo y por ende, poco relevante a nivel macro. Por otro lado, es la dinámica del aumento lo que preocupa, sobre todo porque la tasa no vuelve a bajar en el período posterior a la crisis del año 2009 y, que el aumento del índice de carteras vencidas, coincide con una mayor inflación y empeoramiento de las condiciones en el mercado laboral (Matus et al., 2011: 10).

En resumen, se constata que las suposiciones sobre el aumento de créditos en fase de auge y como consecuencia, mayores problemas de endeudamiento en el contexto de crisis (12 y 13), han sido confirmadas, mientras que las dos tesis referidas a diferencias regionales (11 y 14) no se comprueban: El otorgamiento de créditos de consumo no muestra diferencias importantes y es el resto del país y no las regiones mineras, donde se observa una mayor incidencia de deudores con problemas de pago de sus créditos en momentos coyunturales desfavorables.

Con respecto a la financiarización de los hogares, se vuelve necesario mencionar en este trabajo el rol del sistema de ahorro para la jubilación, las Administradoras de Fondos de Pensiones (AFP). Debido a la obligación por ley que tiene cada empleado de cotizar en este sistema privado de ahorro, eligiendo el nivel de riesgo, se postula de acuerdo con Minsky (15) una tendencia en las fases de auge de cotizar en fondos de mayor riesgo. Además, se espera (16) en el caso de aquellos cotizantes que además hacen uso del sistema de ahorro voluntario (APV), una tendencia de retirar los fondos disponibles en situación de escasez seria - como en una crisis.

Efectivamente para los afiliados que optan, se puede observar una clara tendencia de los cotizantes hacia los fondos de mayor riesgo A y B durante las fases de auge (Figura $N^{\circ} 9$ ). Sin embargo, tal situación cambia durante la crisis, evidenciando una mayor preferencia hacia los fondos más "conservadores" o de menos riesgo. Al pasar la crisis, se observa cómo con el nuevo optimismo los cotizantes tienden a migrar nuevamente hacia fondos de mayor riesgo (Berstein et al., 2011: 5). Además, se demuestra que son los grupos de mayor ingreso los que tienen una participación claramente superior de los fondos A en su cartera (Berstein et al., 2011: 8).

Para la discusión de la financiarización en Chile es importante destacar la liquidez que este sistema - nominalmente de ahorro para la jubilación - provee a las instituciones financieras. El crecimiento del saldo acumulado en años de auge refleja que la liquidez del sistema crece tanto por inyección de capital nuevo como por la rentabilidad del capital acumulado. Pero esto evidentemente no sucede en tiempos de crisis, cuando los mercados bursátiles en descenso provocan que la cartera acumulada pierda valor. Esto es un elemento clave, porque incluso cuando los ahorros de los cotizantes registran pérdidas importantes (Figura No 9), mes a mes, los empleados inyectan "capital fresco" al círculo financiero, proveyendo al sector de liquidez. 
Figura No 9

Volumen total fondos AFP en Chile y cotización en fondos de alto riesgo

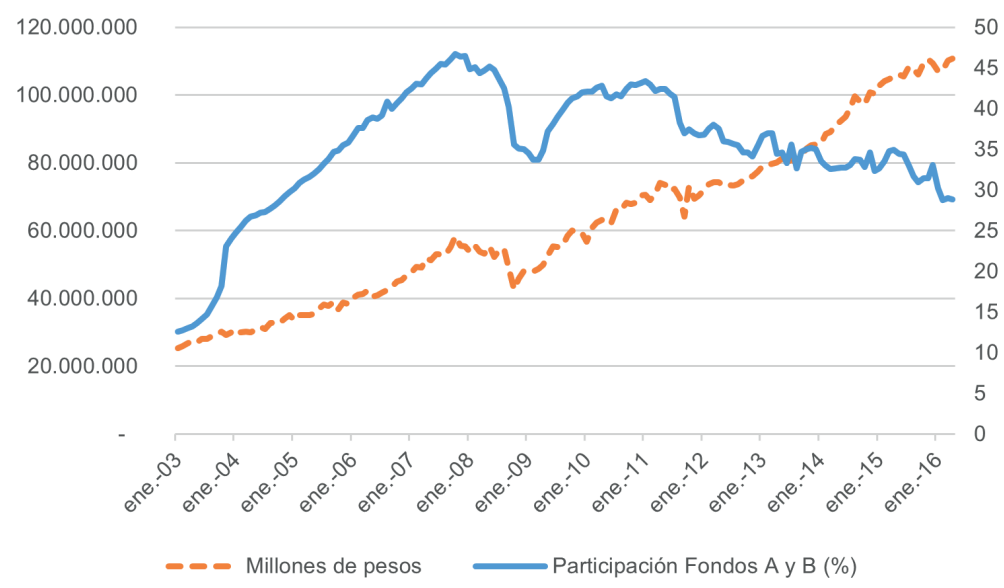

Fuente: Elaboración propia basado en datos de Superintendencia de Pensiones (2016)

Figura No 10

Volumen retiros fondos APV (en millones \$)

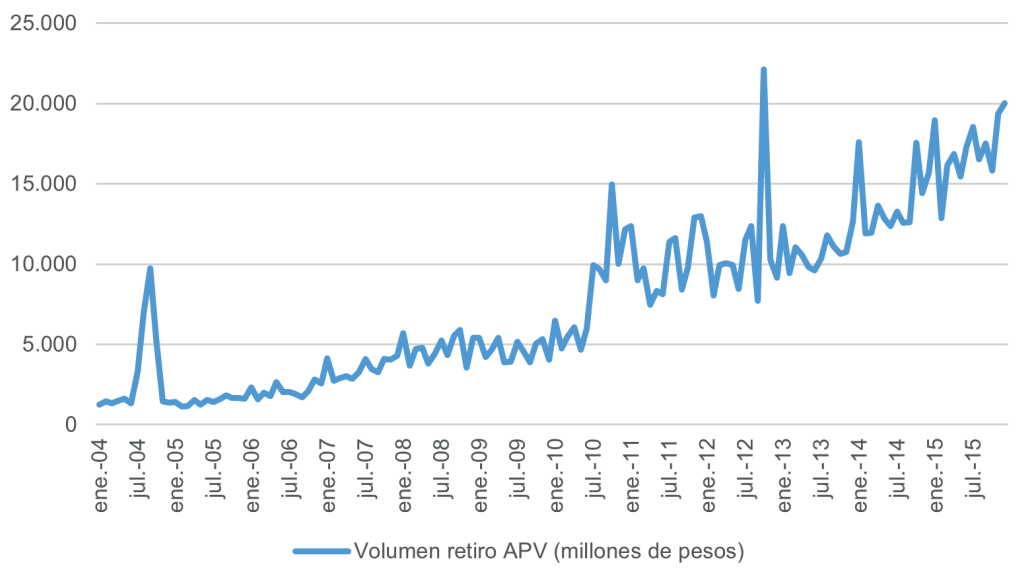

Fuente: Elaboración propia basado en datos de Superintendencia de Pensiones (2016)

Referido al valor de los retiros realizados por los cotizantes de los APV (Figura No 10), se observa que aumentan considerablemente después de la crisis. Resulta notable, que los retiros no se produjeron durante la crisis, como se esperaba, sino que de forma posterior. Posiblemente durante la crisis las personas han perdido confianza en los diferentes instrumentos financieros, y apenas se recuperó el valor de los fondos, se produjo un retiro considerable. Consistente con esto se puede suponer que el flujo de capital desde las APV haya impulsado a la inversión en el sector inmobiliario, debido a que este sector se consideraba relativamente más seguro. 
En resumen, se constata que la tesis 15 se sostiene, mientras que la tesis 16 no se cumplió. En general, los datos muestran la importancia de la liquidez financiera producida por este sistema de ahorro y también, el comportamiento de inversionista que poseen los cotizantes. Si bien los AFP no pueden invertir en inmuebles, el ingreso continuo de capital produce liquidez del sistema financiero en su totalidad, lo que significa que mayores recursos están disponibles para ser otorgados como créditos e invertirlos.

En definitiva, este apartado evidenció que las fases coyunturales marcadas por la exportación, como también la espacialidad de esta actividad, guardan estrecha relación con el ahorro y el endeudamiento de los hogares: la mayoría de los indicadores suben y bajan de acuerdo a la coyuntura. Destaca que la morosidad y el porcentaje de las colocaciones vencidas aumentan con la crisis 2008/2009, sin que se reduzca de manera importante en la fase de recuperación, lo que se traduce en un riesgo de estabilidad y una amenaza financiera para los hogares respectivos. Debido al comportamiento de los créditos hipotecarios, es posible deducir que el capital financiero generado por el sector exportador influye en la inversión inmobiliaria, reaccionando a las marcadas fases de auge y crisis en la exportación a nivel nacional. A continuación, se discute esta relación para el caso de la ciudad de La Serena.

\section{Caso de estudio: La Serena}

Para profundizar la relación entre la renta exportadora, el ciclo financiero y el crecimiento de la ciudad, se presenta a la ciudad de La Serena como un caso de estudio, siendo esta parte de la conurbación La Serena - Coquimbo, principal aglomeración urbana del norte del país. Esta ciudad ha experimentado un acelerado crecimiento poblacional en los últimos años, en el período 2005 - 2013 mostró un crecimiento promedio anual de un 2,31\%, cifra por sobre ciudades mineras del norte del país como Antofagasta y Copiapó con un 1,61\% y 2,07\% respectivamente; ciudades del sur del país como Concepción y Temuco con un 1,01\% y 1,27\% respectivamente; y el promedio a nivel nacional correspondiente a un 1,09\% (Rehner et al., en prensa).

Esto último tiene evidentemente un impacto en la mancha urbana de las ciudades, donde la conurbación La Serena - Coquimbo evidenció un crecimiento de un 2,86\% en el período 2005 - 2013, cifra superior al 0,53\% de Antofagasta y al 1,61\% de Concepción. Tal crecimiento puede vincularse a las casi 40.000 unidades de vivienda nueva en esta conurbación, correspondiente a un crecimiento del 39\% en diez años (INE, 2012). En términos de empleo, La Serena - Coquimbo mostró un crecimiento de un 4,86\% en el período 2005 - 2013, cifra superior al 2,34\% de Concepción, pero inferior a ciudades como Antofagasta y Temuco, con un 5,07\% y 5,36\% respectivamente (Rehner et al., en prensa). Por último, respecto al PIB, Daher (2015) plantea que la región de Coquimbo evidenció el mayor crecimiento del PIB en el período 1970 - 2010, pasando de un $1,53 \%$ a un $2,36 \%$ en su participación al producto nacional. La elección de La Serena como área de estudio se justifica por lo siguiente:

- Actividades mineras: en la región de Coquimbo se han desarrollado en los últimos quince años importantes actividades mineras, mostrando un rápido incremento del empleo y las remuneraciones en este sector, por lo que se espera que parte de los ingresos provenientes de la minería se materialicen en la ciudad (Rehner et al., 2015). 
- Conmutación a larga distancia: la región de Coquimbo tiene además un papel clave en los viajes a larga distancia, enviando trabajadores principalmente al norte del país y con especial énfasis a la región de Antofagasta (Aroca \& Atienza, 2008). Los ingresos obtenidos por estos trabajadores en otras regiones, se traducen en ingreso adicional para la región de Coquimbo y la ciudad de La Serena.

- Reputación y calidad de vida: se supone que esta renta se materializa en La Serena debido a la positiva reputación de esta ciudad en términos de calidad de vida, lo que se expresa también en migraciones por amenidades, generalmente provenientes de ciudades mineras u otras con percepción negativa en términos de calidad de vida (Rodrigo \& Atienza, 2014).

- Inversión en la casa propia: la ciudad de La Serena se presenta como un destino de importancia para familias y personas jubiladas - en parte ligadas al rubro de la minería - invierten en vivienda propia. Sumado a una política urbana que ha fomentado la oferta de infraestructura y servicios turísticos en la ciudad, esto ha generado un fuerte aumento de viviendas (Hidalgo et al., 2009).

- Atractivo turístico: entre los factores que sustentan a La Serena como centro turístico a nivel nacional, se encuentran el carácter de patrimonio histórico, atractivos culturales, paisajísticos, reservas naturales en su cercanía y playas en la misma ciudad (Saldívar, 2012). Esto, ha transformado a la conurbación La Serena - Coquimbo en el tercer destino turístico de mayor preferencia para los turistas a nivel nacional (Sernatur, 2013). Esto ha sido fomentado por el auge minero, periodo en cual la llegada de turistas aumentó rápidamente - en el periodo total analizado (2005-2015) la cantidad de pernoctaciones subió en un $22 \%$.

- Mercado Inmobiliario: a una escala geográfica mayor se evidencia que los precios de vivienda en la zona norte del país han vivido el aumento más drástico en el período 20022013. Además, la tendencia de aumento de precios de los inmuebles en la misma zona norte, sorprendentemente ha continuado incluso durante la crisis subprime (Banco Central de Chile, 2014: 15).

\section{La inversión inmobiliaria en la ciudad de La Serena}

Como resultado de estas características, La Serena ha sido importante receptor de inversión inmobiliaria en los últimos años. El presupuesto de los permisos de edificación para vivienda nueva, presenta una clara tendencia al alza en el período 2005 - 2015, prácticamente cuadruplicando su valor mensual en este período (Figura No 11). Esta tendencia está acompañada de una fuerte volatilidad, destacando tres fases principales, correspondientes en primer lugar al crecimiento sostenido durante la fase de auge, seguido por la fuerte caída experimentada durante la crisis en el año 2009 y se prolonga en parte de 2010, situándose casi en la totalidad de este periodo por debajo de la tendencia general. Por último, un tercer momento corresponde a la recuperación posterior a la crisis, marcada por un fuerte ascenso en la inversión inmobiliaria presupuestada, que dura hasta inicios de 2013, para luego experimentar un leve descenso que se prolonga hasta fines de 2015, momento en cual se observa un salto irregular, probablemente debido a cambios en la normativa (introducción del IVA a la vivienda nueva a partir de 2016). Es importante destacar 
que el indicador refleja el presupuesto de las obras aprobadas por la Municipalidad de La Serena esto no significa que esta obra se realizó efectivamente, ni mucho menos que costó efectivamente lo presupuestado, sino que corresponden a una estimación oficial. Sin embargo, se destaca que es un indicador de los flujos financieros, lo cual refleja la disposición de invertir, situación que no refleja el mero número de permisos o los metros cuadrados.

\section{Figura No 11}

Presupuesto permisos de edificación otorgados para vivienda nueva

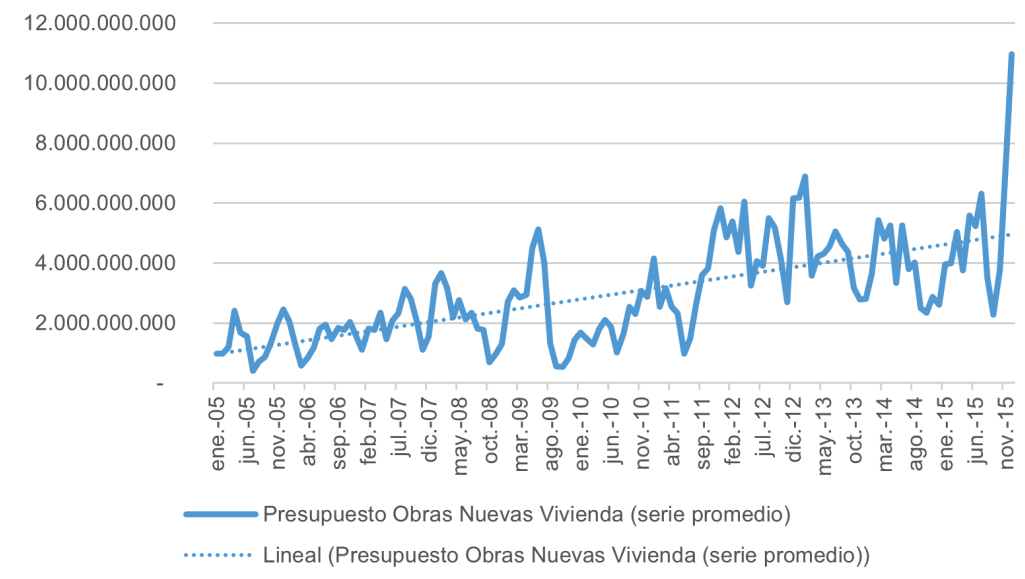

Fuente: Elaboración propia basado en datos de DOM La Serena

\section{Los modelos de regresión para estimar la inversión en vivienda}

Empleando el valor presupuestado de las obras de construcción como indicador de la inversión inmobiliaria, permite conocer en qué medida las variables asociadas al auge exportador y a la financiarización generan fases de crecimiento inmobiliario en ciudades consideradas atractivas. Sumando a estos dos aspectos, se supone que el crecimiento de la inversión inmobiliaria se debe en parte a la dinámica poblacional de la comuna, que demanda nuevas viviendas. Por esto, un primer ejercicio consistió en calcular una simple regresión, estimando la inversión inmobiliaria en función del crecimiento poblacional, lo que mostró que la variable población posee gran importancia en explicar el presupuesto de la construcción de vivienda en La Serena ( $R^{2}$ de 0,504, significancia 0,0 y beta estandarizado de 0,712). Sin embargo, esto no implica más que la constatación obvia que el crecimiento poblacional va acompañado por un aumento de la inversión en vivienda. Dado esto, se sumaron otras variables basadas en la discusión teórica anteriormente presentada, suponiendo que ellas pueden aportar explicaciones causales para el análisis del crecimiento y de sus variaciones más allá del aumento poblacional.

Los resultados de dos modelos de regresión evidencian la importancia que tiene en primer lugar, el valor total de los fondos acumulados en la AFP (beta de 0,363 y 0,650 en los dos modelos), en explicar el comportamiento de la inversión inmobiliaria en la ciudad de La Serena. Esta variable explicativa es seguido por el monto de los retiros de las APV (sólo en el primer modelo, beta 0,259 ) y el valor de la exportación en minería (en ambos modelos, beta 0,208 y 0,1919). 
Como parte importante de este resultado vale destacar que las variables "población", "remuneraciones" y "créditos hipotecarios", quiere decir aquellas variables que representan la demanda efectiva por necesidad de vivienda, el ingreso disponible y el endeudamiento, muestran multicolinealidad muy elevada, por lo cual han sido eliminados sucesivamente del modelo y finalmente los mejores modelos son aquellos que no consideran estas variables. Caso aparte corresponde al crecimiento de las colocaciones bancarias, variable que muestra una relación negativa con la variable dependiente y un nivel de significancia insatisfactorio.

Cuadro No 2

Modelos de Regresión

\begin{tabular}{|c|c|c|c|c|c|c|}
\hline \multirow{3}{*}{ Variables } & \multicolumn{6}{|c|}{ Presupuesto permisos de edificación obra nueva vivienda La Serena } \\
\hline & \multicolumn{2}{|c|}{ Modelo inicial } & \multicolumn{2}{|l|}{ Modelo 1} & \multicolumn{2}{|l|}{ Modelo 2} \\
\hline & Sig & $\begin{array}{c}\text { Colinealidad } \\
\text { (VIF) }\end{array}$ & $\begin{array}{c}\text { Beta } \\
\text { estandarizado }\end{array}$ & Sig & $\begin{array}{c}\text { Beta } \\
\text { estandarizado }\end{array}$ & Sig \\
\hline Población & $\operatorname{sig}$ & 210,998 & & & & \\
\hline $\begin{array}{l}\text { Colocaciones bancarias } \\
\text { nuevas }\end{array}$ & sig & 1,175 & & & $-0,142$ & 0,032 \\
\hline $\begin{array}{l}\text { Volumen créditos } \\
\text { hipotecarios }\end{array}$ & n.s. & 65,272 & & & & \\
\hline Número de pernoctaciones & n.s. & 1,211 & & & & \\
\hline $\begin{array}{l}\text { Remuneración promedio } \\
\text { otros rubros }\end{array}$ & sig & 238,770 & & & & \\
\hline $\begin{array}{l}\text { Valor de la exportación en } \\
\text { minería }\end{array}$ & sig & 2,038 & 0,208 & 0,006 & 0,191 & 0,010 \\
\hline $\begin{array}{l}\text { Volumen acumulado } \\
\text { cotizaciones en AFP }\end{array}$ & sig & 44,733 & 0,363 & 0,029 & 0,650 & 0,00 \\
\hline Monto de los retiros en APV & n.s. & 7,267 & 0,259 & 0,103 & & \\
\hline $\begin{array}{l}\text { Remuneración promedio } \\
\text { minería (mensual) }\end{array}$ & n.s. & 67,588 & & & & \\
\hline Balance Financiero de Cartera & n.s. & 1,264 & & & & \\
\hline R2 Ajustado & & 0,570 & 0,529 & & 0,536 & \\
\hline
\end{tabular}

Fuente: Elaboración propia.

Nota: Los valores que se muestran son significativos (menor a 0,11 ). El $R^{2}$ ajustado de cada uno de los modelos demuestra el grado de determinación del modelo de regresión construido. Se demuestran solamente modelos significativos (al nivel 0,005). El test de colinealidad muestra valores satisfactorios: Tolerancia $>0,1$; FIV $<7,0$. Respecto a la significancia de cada variable, * es $<a 0,05$, ** es $<a 0,01 y^{* * *}<a 0,001$.

\section{El auge exportador y su relación con la inversión inmobiliaria en La Serena}

Una primera interpretación de los resultados obtenidos es que el auge exportador en Chile asociado principalmente a la minería de cobre y la producción de cobre refinado, se encuentra 
estrechamente ligado con la actividad constructora en la comuna de La Serena. La interpretación se sustenta en que según el modelo, se puede constatar que con un aumento del valor de la exportación minera a escala nacional, el presupuesto de los permisos de edificación otorgados para vivienda nueva en La Serena experimenta un aumento también, tal como se visualiza en los valores para beta estandarizado (Cuadro $N^{\circ} 2$ ).

Esto fundamenta la reflexión del traspaso de escalas del efecto de ingreso. Si bien los ingresos por exportación minera se generan a nivel nacional, sus impactos en la comuna son relevantes, aterrizando en la ciudad y materializándose en la inversión inmobiliaria en la ciudad de La Serena. Es posible argumentar que no sólo el ingreso generado por la minería localizada en la región de Coquimbo impacta de manera significativa en esta ciudad, sino que debido a la conmutación a larga distancia (Aroca \& Atienza, 2008), es también la exportación generada en otras regiones, como Atacama, Tarapacá y por sobre todo Antofagasta, lo que explicarían en parte la inversión en nuevas viviendas en La Serena. Esto coincide con la apreciación de la Cámara de Construcción local, donde se afirma que altos porcentajes de la demanda de vivienda en la región de Coquimbo, corresponden a segunda vivienda que adquieren trabajadores mineros de otras regiones del norte del país (Minería Chilena, 2015).

Así, un elemento clave de este análisis corresponde entonces a las remuneraciones de los trabajadores del sector minero. Al respecto, se esperaba que las remuneraciones obtenidas por los trabajadores mineros, tuviesen un impacto significativo en explicar la inversión inmobiliaria en la ciudad de La Serena, debido a que son ellos importantes receptores de la liquidez generada por exportación y por ende, se esperaba la inversión de esta liquidez a largo plazo, por ejemplo en una vivienda nueva. Sin embargo, los resultados en los modelos de regresión no mostraron valores estadísticamente significativos, y debido a la alta colinealidad que presentó esta variable, se decidió apartarla del análisis realizado. Aun así, esto no significa que la remuneración no tendría importancia, sino que, considerando que un porcentaje elevado se asocia con la inversión para la jubilación de trabajadores mineros de otras regiones (Minería Chilena, 2015), significa que la inversión en vivienda en La Serena se relaciona con ingresos logrados en otros espacios y en otros tiempos, por lo cual no puede ser demostrada una correlación estadística.

\section{La liquidez financiera y su relación con la inversión inmobiliaria en La Serena}

La liquidez de las instituciones financieras representa un factor de gran importancia para explicar el comportamiento de la inversión inmobiliaria en la ciudad de La Serena. Al respecto, las variables expresadas en términos del volumen total de las cotizaciones en AFP y el monto total de los retiros en APV, tienen un comportamiento similar, existiendo diferencias en el peso que posee cada una de ellas en explicar la variable dependiente para este caso (beta estandarizado en el Cuadro No 2). En particular, se observa que cuando el volumen acumulado de los fondos de AFP aumenta, la inversión inmobiliaria también lo hace. Esto resulta ser llamativo, ya que el capital financiero asociado a las AFP se encuentra a una escala nacional y móvil en el espacio, pero este no puede ser invertido en inmuebles. Sin embargo, se evidencia que la disponibilidad de capital financiero -representado a través de la valoración de los AFP-, se materializa en la construcción de viviendas nuevas en La Serena. 
Asimismo, los resultados del primer modelo de regresión demuestran que el monto de los retiros de los APV explica en parte la dinámica en la construcción de viviendas en La Serena, aunque con un peso menor que las AFP. Cuando aumenta el monto de los retiros en APV, la inversión inmobiliaria aumenta en La Serena, siendo un indicio para una posible preferencia de los hogares de mover recursos financieros del sistema de ahorro institucional a la inversión en inmuebles.

En cuanto a las colocaciones bancarias, se observa una tendencia que difiere de lo esperado, según lo planteado en el apartado teórico. Principalmente en el planteamiento de David Harvey se combina el argumento de la liquidez excesiva con el endeudamiento como mecanismo de opresión. Dado que se evidenció que la liquidez financiera posee gran relevancia al momento de explicar la dinámica de inversión inmobiliaria en La Serena, se podría esperar que esto vaya acompañado por un aumento de créditos hipotecarios. Sin embargo, los resultados no muestran una relación estadísticamente sólida, e incluso se reconoce en el segundo modelo una relación negativa, es decir, cuando disminuyen las colocaciones, la inversión inmobiliaria aumenta, aunque este resultado tiene poco peso estadístico (Beta estandarizado de -0,142).

En definitiva, a partir de los resultados obtenidos en el presente apartado, es posible sostener el argumento de que el ingreso de capital generado por el sector exportador tiene un peso importante en explicar el comportamiento temporal de la inversión inmobiliaria. Por otro lado, es la disponibilidad de capital financiero, generado internamente a través del ingreso en combinación de la coyuntura en los mercados de valores, medido por el valor de los fondos de pensiones, el que explica de forma importante la inversión inmobiliaria presupuestada en la ciudad de La Serena, apoyada además por los retiros de fondos del sistema APV. Asimismo, se constata que ambos flujos de capital tienen una estrecha relación con las fases de auge y crisis económica, lo que finalmente se traduce en una mayor (auge) y menor (crisis) inversión inmobiliaria en esta ciudad. Finalmente, es importante destacar que los resultados obtenidos en La Serena no sostienen el supuesto que el endeudamiento, a través de los créditos hipotecarios, es un motor importante de la inversión inmobiliaria.

\section{Conclusiones}

En base al análisis de la situación a escala país se ha demostrado cómo la liquidez financiera, el ahorro de los hogares y el otorgamiento de los créditos en Chile se asocian a los ciclos de auge y crisis, recuperación y estagnación. Además, se evidencia una tendencia de la inversión de los hogares a través de los AFP hacia fondos de mayor riesgo en fases de auge. Todas estas observaciones concuerdan con el planteamiento de Minsky (Wolfson, 2002). Adicionalmente se ha evidenciado una tendencia hacia mayor inversión inmobiliaria en tiempos de auge, tal como lo esperaríamos basado en las propuestas tanto de Harvey (2011) como de Sachs \& Warner (2001). Esta tendencia puede ser interpretada por un lado, como parte del segundo circuito del capital y manifestación de la reinversión del exceso de liquidez, y por otro lado, como una reacción racional de protección frente a la volatilidad de la renta exportadora a través de la inversión a largo plazo.

Evidentemente la fase de auge tiene su fundamento principal en la exportación, destacando en este sentido la diferencia entre regiones mineras y no mineras, donde las primeras reaccionan de forma más directa a las fases de auge. El planteamiento de Minsky considera tal posibilidad, en 
cual un auge financiero es generado por la exportación impulsada por la demanda externa. Si bien la crisis posterior no se asocia directamente a una reducción del ingreso de inversión del extranjero y aparentemente tampoco el endeudamiento de los hogares ha sido causa importante de la crisis en el caso de Chile, el endeudamiento muestra un aumento considerablemente en los últimos diez años, situándose en un nivel problemático posterior a la crisis del período 2008/2009, lo que implica que tal situación se podría transformar en un problema real, asociado principalmente a la morosidad en la que incurren estos agentes económicos.

A escala ciudad, las tendencias muestran que la inversión inmobiliaria en La Serena está dado en gran medida por los flujos de capitales provenientes de la exportación y el sistema financiero, expresado en el valor de los fondos de pensiones de AFP y los retiros de APV. Asimismo, si bien se constató una fuerte volatilidad en la inversión inmobiliaria de esta ciudad, se puede concluir que las marcadas fases de auge y crisis vistas a nivel nacional y que responden en gran medida al contexto internacional, tienen influencia en las tendencias y comportamiento de la inversión inmobiliaria en La Serena. Es notable que el supuesto de un importante papel de los créditos hipotecarios en la explicación de la actividad inmobiliaria parece no tener lugar en el caso de La Serena, donde la inversión inmobiliaria no muestra relación estadísticamente significativa con el otorgamiento de créditos, por lo que se deduce que el crecimiento urbano de la ciudad no está dado por el endeudamiento de los hogares.

Si bien los resultados tendrán que ser contrastados con modelos para otras ciudades, tanto aquellas explícitamente ligadas al sector minero como también ciudades ajenas a esta actividad exportadora, destaca la importancia de la financiarización que traspasa las escalas. Además - a raíz de la actual crítica al sistema AFP - resultados del presente trabajo también se pueden interpretar como una muestra de la relevancia de un mecanismo estabilizador que representa una de las perversidades internas de un sistema financiero: durante la fase de crisis son los empleados que inyectan permanentemente liquidez al circuito financiero, haciendo con sus cotizaciones un aporte a la estabilidad del sistema financiero, pero asimismo, son los ahorros de ellos los que precisamente se desvalorizan. $\mathrm{Si}$, además, se daría el escenario posible que debido a la financiarización, los valores generados en la ciudad a través del mercado inmobiliario se basan en una "fantasía" que se aleja de la demanda real, la posibilidad de derrumbe es particularmente amenazante para los hogares, ya que sus mayores activos perderían valor.

\section{Referencias bibliográficas}

ARBOLEDA, M. Financialization, totality and planetary urbanization in the Chilean Andes. Geoforum, 2015, N 67, p. 4-13.

AROCA, P. y ATIENZA, M. La Conmutación Regional en Chile y su Impacto en la Región de Antofagasta. EURE, 2008, Vol. 34, No 102, p. 97-121.

ARRAÑO, E. y VELÁSQUEZ, B. Estadísticas de Colocaciones. Santiago de Chile: Estudios Económicos Estadísticos, Banco Central de Chile, 2012, № 92, p. 1-28.

BANCO CENTRAL DE CHILE. Estadísticas de colocaciones bancarias. Santiago de Chile: Banco Central de Chile, 2016a. 
BANCO CENTRAL DE CHILE. Estadísticas monetarias y financieras. Santiago de Chile: Banco Central de Chile, 2016b.

BANCO CENTRAL DE CHILE. Índice de Precios de Vivienda en Chile: Metodología y Resultados. Estudios Económicos Estadísticos N 107. Santiago de Chile: Banco Central de Chile, 2014.

BANCO DE ESPAÑA. Encuesta financiera de las familias (EFF) 2011. Boletín Económico Enero 2014. Madrid: Banco de España, 2014.

BERSTEIN, S.; FUENTES, O. \& TORREALBA, N. Esquema de multifondos en Chile. Santiago de Chile: Documento de Trabajo N 43, Superintendencia de Pensiones, 2011.

BRUECKNER, J.K.; CALEM, P.S. \& NAKAMURA, L.I. Subprime mortgages and the housing bubble. Journal of Urban Economics, 2012, No 71, p. 230-243.

CAMPBELL, S.D.; DAVIS, M.A.; GALLIN, J. \& MARTIN, R.F. What moves housing markets: A variance decomposition of the rent-price ratio. Journal of Urban Economics, 2009, N 66, p. 90-102.

CATTANEO PINEDA, R.A. Los fondos de inversión inmobiliaria y la producción privada de vivienda en Santiago de Chile: ¿Un nuevo paso hacia la financiarización de la ciudad? EURE, 2011, Vol. 37, $N^{\circ} 112$, p. 5-22.

COMISIÓN CHILENA DEL COBRE (COCHILCO). Estadísticas Producción Minera. Santiago de Chile: Comisión Chilena del Cobre, 2016.

COMISIÓN ECONÓMICA PARA AMÉRICA LATINA Y EL CARIBE (CEPAL). Panorama Fiscal de América Latina y el Caribe. Reformas tributarias y renovación del pacto fiscal. Santiago de Chile: Comisión Económica para América Latina y el Caribe, 2013.

CORBO, V.; DESORMEAUX, J. y SCHMIDT-HEBBEL, K. La gran crisis financiera de 2007-2009. Estudios Públicos 2011, N¹23, p. 7-67.

CORDEN, W.M. \& NEARY, J.P. Booming Sector and De-industrialisation in a Small Open Economy. Economic Journal, 1982, Nº 92, p. 825-848.

COREMBERG, A. La productividad de América Latina ante el auge de precios de productos básicos. Cuadernos Económicos de ICE, 2012, № 84, p. 123-153.

CORPATAUX, J.; CREVOISIER, O. \& THEURILLAT, T. The Expansion of the Finance Industry and its Impact on the Economy: A Territorial Approach Based on Swiss Pension Funds. Economic Geography, 2009, Vol. 85, № 3, p. 313-334.

CRONON, W. Nature's Metropolis. New York: W.W. Norton, 1992.

CUEVAS AHUMADA, V. La crisis hipotecaria subprime y sus efectos sobre México. Análisis Económico, 2013, Vol. XXVIII, No 67, p. 123-151. 
DAHER, A. Regiones-commodities: Crisis y contagio en Chile. EURE, 2003, Vol. 29, No 86, p. 89-108.

DAHER, A. El sector inmobiliario y las crisis económicas. EURE, 2013, Vol. 39, N 118, p. 47-76.

DAHER, A. Infación y deflación urbanas: De burbujas inmobiliarias a recesiones económicas. RIEM, 2015, p. 217-242.

DAHER, A. Metropolización en la región de mayor crecimiento de Chile, Coquimbo. AUS, 2015, № 19, p. 45-50.

DAVIS, M.A. \& ORTALO-MAGNÉ, F. Household expenditures, wages, rents. Review of Economic Dynamics, 2011, Vol. 14, No 2, p. 248-261.

DE GREGORIO, J. How Latin America weathered the global financial crisis. Washington D.C.: Peterson Institute for International Economics, 2014.

DE MATTOS, C. Globalizacion, negocios inbobiliarios y mercantilizacion del desarrollo urbano. En: PEREIRA, P.C. y HIDALGO, R. (Editores). Producción inmobiliaria y reestructuración metropolitana en América Latina. Santiago de Chile: Serie Geolibros No 11, Instituto de Geografía-Pontificia Universidad Católica de Chile, 2008, p. 23-40.

FOX GOTHAM, K. Creating Liquidity out of Spatial Fixity: The Secondary Circuit of Capital and the Subprime Mortgage Crisis. International Journal of Urban and Regional Research, 2009, Vol. 33, $N^{\circ} 2$, p. 355-371.

GORTON, G.B. Misunderstanding Financial Crisis. Why we don't see them coming. Oxford: Oxford University Press, 2012.

HANDKE, M. Riesgos Sistémicos en La Crisis Inmobiliaria y Financiera en España. AIOS, 2013, No 1, p. 161-194.

HARVEY, D. Roepke Lecture in Economic Geography-Crises, Geographic Disruptions and the Uneven Development of Political Responses. Economic Geography, 2011, Vol. 87, No 1, p. 1-22.

HARVEY, D. The Urbanization of Capital. Baltimore: John Hopkins University Press, 1985.

HIDALGO, R.; ARENAS, F. y MONSALVE, R. La conurbación La Serena - Coquimbo: Problemas y desafíos de su transición metropolitana. En: HIDALGO, R.; DE MATTOS, C. y ARENAS, F. (Editores). Chile: Del país urbano al país metropolitano. Santiago de Chile: GEOlibros No 8, Instituto de Geografía-Pontificia Universidad Católica de Chile, 2009, p. 161-184.

INSTITUTO NACIONAL DE ESTADÍSTICA (INE). Estadísticas demográficas y vitales: Actualización de población 2002 - 2012 y proyecciones 2013 - 2020. Santiago de Chile: Instituto Nacional de Estadística, 2016.

INSTITUTO NACIONAL DE ESTAdístICA (INE). Resultados Preliminares CENSO de Población y Vivienda. Santiago de Chile: Instituto Nacional de Estadística, 2012. 
ISUNZA VIZUET, G. Desarrollo inmobiliario y capacidad financiera de los municipios del estado de México. En: NOYOLA, J.; DE MATTOS, C.A. y ORELLANA, A. (Editores). Urbanización en tiempos de crisis. Impactos, desafíos y propuestas. Santiago de Chile: Colección Estudios Urbanos UC, 2013, p. 229-256.

LEFEBVRE, H. La Revolución Urbana. Madrid: Alianza Editorial, 1983 orig. 1970.

MARCHAND, J. Local labor market impacts of energy boom-bust-boom in Western Canada. Journal of Urban Economics, 2012, № 71, p. 165-174.

MATUS, J.M.; SILVA, N.; MARINOVIC, A. y FLORES, K. Una visión global de la deuda financiera de los hogares chilenos en la última década. Santiago de Chile: Banco Central de Chile, Estudios Económicos Estadísticos, 2011, № 81.

MÉNDEZ, R. Impactos de la crisis internacional en la Región Metropolitana de Madrid. En: NOYOLA, J.; DE MATTOS, C. y ORELLANA, A. (Editores). Urbanizacion en tiempos de crisis. impactos, desafíos y propuestas. Santiago de Chile: Colección Estudios Urbanos UC, 2013, p. 45-71.

MINERÍA CHILENA. Desarrollo inmobiliario y minería: El notorio crecimiento en la Región de Coquimbo. Minería de Chile, 09 de 06 de 2015. Disponible en Internet: http://www.mch.cl/reportajes/desarrollo-inmobiliario-y-mineria-el-notorio-crecimiento-en-la-region-de-coquimbo/

MINISTERIO DE VIVIENDA Y URBANISMO. (MINVU). Estadísticas de Subsidios Observatorio Habitacional MINVU. Santiago de Chile: MINVU, 2014.

MORADBEIGI, M. \& LAW, S.H. Economic Growth Volatility and Resource Curse: The Role of Financial Development . Taylor's Business Review, 2014, Vol. 4, N² 2, p. 147-164.

PHELPS, N.; ATIENZA, M. \& ARIAS, M. Encore for the Enclave: The Changing Nature of the Industry Enclave with Illustrations from the Mining Industry in Chile. Economic Geography, 2015, Vol. 91, No 2, p. 119-146.

PIKE, A. \& POLLARD, J. Economic Geographies of Financialization. Economic Geography, 2010, Vol. $86, N^{\circ} 1$, p. 29-51.

RAINES, J.P. \& LEATHERS, C.G. Debt, Innovations, and Deflation. The Theories of Veblen, Fisher, Schumpeter, and Minsky. Cheltenham: Edward Elgar, 2008.

RAMÍREZ DE LA O, R. México en la crisis global y en su propia crisis: ¿Qué Hacer? México D.F.: Fundación Friedrich Ebert, México, 2009.

REHNER, J.; BAEZA, S. y BARTON, J. En hombros de gigantes: Una geografía económica del comercio Chile-Asia. Santiago de Chile: GEOlibros No 20, Instituto de Geografía-Pontificia Universidad Católica de Chile, 2015.

REHNER, J.; BAEZA, S. \& BARTON, J. Chile's resource-based export boom and its outcomes: Regional specialization, export stability and economic growth. Geoforum, 2014, No 56, p. 35-45. 
REHNER, J.; RODRÍGUEZ-LEIVA, S. y MURRAY, W. Ciudades en auge en Chile: Rol de la actividad exportadora en la dinámica del empleo urbano. EURE, en prensa.

REINHART, C.M. \& ROGOFF, K.S. This time is different. Princeton: Princeton University Press, 2009.

RODRIGO, L. y ATIENZA, M. Migración y representaciones regionales: discursos sobre la región de Antofagasta. EURE, 2014, Vol. 40, № 120, p. 159-181.

SACHS, J.D. \& WARNER, A.M. The curse of natural resources. European Economic Review, 2001, No 45, p. $827-838$.

SALDÍVAR, R. La Serena goza actualmente de una explosión inmobiliaria. El Mercurio, 13 de mayo de 2012. Disponible en Internet:

http://www.edicionesespeciales.elmercurio.com/destacadas/detalle/index.asp?idnoticia=20120513998786.

SERVICIO NACIONAL DE TURISMO (SERNATUR). Perfil del turista chileno 2012. Santiago de Chile: Inforgráfico SERNATUR, 2013.

SILVA, C. G. y VIO, C. Los precios de vivienda y factores macroeconómicos: el caso de Chile. Economía Chilena, 2015, Vol. 18, №1, p. 4-24.

SUPERINTENDENCIA DE BANCOS E INFORMACIÓN FINANCIERA (SBIF). Superintendencia de Bancos e Información Financiera: Información Regional. Santiago de Chile: SBIF, 2015.

SUPERINTENDENCIA DE BANCOS E INFORMACIÓN FINANCIERA (SBIF). Superintendencia de Bancos e Información Financiera: Información Financiera, tarjetas. Santiago de Chile: SBIF, 2016.

SUPERINTENDENCIA DE PENSIONES. Centro de Estadísticas. Santiago de Chile: Superintendencia de Pensiones, 2016.

WALDRON, R. The 'Unrevealed Casualties' of the Irish Mortgage Crisis: Analysing the Broader Impacts of Mortgage Market Financialisation. Geoforum, 2016, No 69, p. 53-66.

WOLFSON, M.H. Minsky's theory of financial crisis in a global context. Journal of Economic Issues, 2002, Vol. 36, No 2, p. $393-400$. 